\title{
Kinetics of oxidation of nickel(II) aza macrocycles by peroxydisulphate in aqueous media
}

\author{
J LALITHAM and V R VIJAYARAGHAVAN* \\ Department of Physical Chemistry, University of Madras, Guindy Campus, \\ Chennai 600 025, India \\ e-mail: lalitham26@yahoo.com
}

MS received 3 May 2000; revised 1 July 2000

\begin{abstract}
The kinetics of the oxidation of nickel (II) hexaaza and nickel (II) pentaaza macrocycles by the peroxydisulphate anion, $\mathrm{S}_{2} \mathrm{O}_{8}{ }^{2-}$, were studied in aqueous media. Effect of $p \mathrm{H}$ on reaction rate was also studied. The rate increases with increase of $\mathrm{S}_{2} \mathrm{O}_{8}{ }^{2-}$ concentration. Rates are almost independent of acid between $p \mathrm{H} 4$ and 2, giving overall a relatively simple second-order rate law followed by oxidation within the ion pair solvent shell. Using rate $=+1 / 2 \mathrm{~d}\left[\mathrm{Ni}(\mathrm{L})^{3+}\right] / \mathrm{d} t=k\left[\mathrm{Ni}(\mathrm{L})^{2+}\right]\left[\mathrm{S}_{2} \mathrm{O}_{8}{ }^{2-}\right]$, oxidation rate constants were determined.
\end{abstract}

Keywords. Kinetics; oxidation; peroxydisulphate; Ni(II) hexaazamacrocycle; Ni(II) pentaaza macrocycle.

\section{Introduction}

The chemical behaviour of transition-metal complexes often depends on their redox properties. This is true to a large extent for the natural and synthetic complexes involving macrocyclic ligands such as $\mathrm{Ni}$ (II) hexaaza and pentaaza macrocyclic derivatives which are known to display properties and reactivity very close to those of the cyclam analogue and have been documented in literature ${ }^{1}$. Encircling a Ni(II) centre by the 14-membered tetramine macrocycle cyclam allows access to the otherwise unstable $\mathrm{Ni}(\mathrm{III})$ and $\mathrm{Ni}(\mathrm{I})$ oxidation states. Interestingly both trivalent and monovalent species have been shown to display unusual reactivity. In particular (i) Ni(III) complexes of cyclam and cyclam-like ligands play a catalytic role in DNA modification under oxidative conditions ${ }^{2}$ and in the homogeneous oxidation of cyclohexene and arylalkenes to epoxides ${ }^{3}$ and (ii) the $\mathrm{Ni}(\mathrm{I})$ complexes of cyclam has been proved to mediate the electrochemical reduction of $\mathrm{CO}_{2}{ }^{4-8}$ and alkyl halides ${ }^{9,10}$. Any modification of the 14 membered framework (variation of ring size, introduction of alkyl substituents, introduction of variable degrees of unsaturation etc.) drastically reduces the catalytic efficiency in both processes of types (i) and (ii).

Almost all $\mathrm{Ni}(\mathrm{II})$ macrocyclic complexes investigated so far, display the typical macrocyclic inertness towards demetallation by strong acids ${ }^{11}$. Most of the $\mathrm{Ni}$ (II) complexes have been isolated as perchlorate salts by the addition of concentrated perchloric acid to the reaction solution. These salts are water soluble and show an extreme kinetic stability, in complete analogy with that found with the corresponding cyclam complexes.

*For correspondence 
$\mathrm{Xu}$ and McAuley have used $\mathrm{S}_{2} \mathrm{O}_{8}{ }^{2-}$ preparatively to oxidize macrobicyclic $\mathrm{Ni}$ (II) complexes but found the kinetics intractable due to side reactions of the $\mathrm{SO}_{4}^{-}$radicals ${ }^{12}$. Kinetics and mechanism of oxidation of $\mathrm{Ni}(\mathrm{II})$ tetraazamacrocycles by $\mathrm{S}_{2} \mathrm{O}_{8}{ }^{2-}$ anion in aqueous and binary aqueous mixtures have been reported ${ }^{12}$ and a similar report on bis(1,4,7-triazacyclononane) $\mathrm{Ni}$ (II) is found in literature ${ }^{13,14} \cdot \mathrm{S}_{2} \mathrm{O}_{8}{ }^{2-}$ has been used to prepare aqueous solutions of $\mathrm{Ni}$ (III) polyaza macrocycles ${ }^{15}$. A pulse radiolytic study of the oxidation of $\mathrm{Ni}(\mathrm{II})$ complex with an unsaturated macrocyclic ligand $\mathrm{by}_{\mathrm{Br}}{ }^{-}$and $\mathrm{OH}^{-}$ radicals in aqueous solutions ${ }^{16}$ has been reported. Many kinetic studies have shown the $\mathrm{Ni}$ (II) complex to be smoothly oxidized to the +3 state by a variety of oxidants via an outer-sphere mechanism ${ }^{17}$.

Since any modification in the framework of macrocycles such as variation of ring size, introduction of alkyl substituents, unsaturation etc. have been shown to affect the redox properties of macrocycles, different types of macrocycles such as hexaaza (polycyclic and monocyclic) and pentaaza (dienes and $\mathrm{CH}_{3}$-substituted dienes) are chosen for our present work. The kinetics of oxidation of two $\mathrm{Ni}$ (II) hexaaza and two $\mathrm{Ni}$ (II) pentaaza macrocycles, $[\mathrm{Ni}(\mathrm{II}) \mathrm{L}]^{2+}$, by $\mathrm{S}_{2} \mathrm{O}_{8}{ }^{2-}$ have been studied as a function of $\mathrm{S}_{2} \mathrm{O}_{8}{ }^{2-}$ and $p \mathrm{H}$ and are reported in this paper.

\section{Experimental}

\subsection{Materials}

The $\mathrm{Ni}(\mathrm{II}) \mathrm{L}^{1} \quad\left[\left(\mathrm{~L}^{1}=1,3,6,9,11,14\right.\right.$-hexaazatricyclo $\left.(12,2,1,1)\right)$ octadecane $]$ perchlorate complex was prepared by a reported procedure ${ }^{18,19}$. Complexes $\mathrm{Ni}$ (II) $\mathrm{L}^{2}, \mathrm{Ni}(\mathrm{II}) \mathrm{L}^{3}$ and $\mathrm{Ni}$ (II) $\mathrm{L}^{4}$ were also synthesised as perchlorates, vide the procedure reported in the literature ${ }^{20}$. AnalaR grade sodium peroxydisulphate $(\mathrm{CDH})$ was used as such. Lithium perchlorate was prepared by neutralization of lithium carbonate (AR) with $\mathrm{HClO}_{4}$ and was recrystallized from water. All other reagents and solvents were of AnalaR Grade and were used without further purification. All solutions were prepared using doubly distilled deionised water.<smiles>C1CN2CCNN(CCNCN1)CC2</smiles>

$L^{1}$<smiles>C1=NC=NCCNCNCNC1</smiles>

$L^{3}$<smiles>C1CNCCNCCNCCNCCN1</smiles>

$L^{2}$<smiles>CC1=NCCNCNCNCCN=C(C)C1</smiles>

$L^{4}$ 


\subsection{Structures of ligands $L^{1}-L^{4}$}

The structures of ligands used in this work are as below:

$$
\begin{aligned}
& \mathrm{L}^{1}=1,3,6,9,11,14 \text {-hexaazatricyclo }(12,2,1,1,) \text { octadecane, } \\
& \mathrm{L}^{2}=1,3,6,9,11,14 \text {-hexaazacyclohexadecane, } \\
& \mathrm{L}^{3}=1,4,6,8,11 \text {-pentaazacyclotrideca } 11,13 \text {-diene, } \\
& \mathrm{L}^{4}=12,14 \text {-dimethyl,1,4,6,8,11-pentaazacyclotetradeca-11,14-diene. }
\end{aligned}
$$

\section{Kinetics}

Kinetic studies were performed under pseudo-first-order conditions using an excess of peroxydisulphate. Concentrations of the $\mathrm{Ni}$ (II) complexes used in this experiment were in the range $2-5 \times 10^{-3} \mathrm{~mol} \mathrm{dm}^{-3}$. Changes in absorbance over time were measured using a C-160 MK II spectrophotometer (AIMIL). A constant perchloric acid concentration of $0.01 \mathrm{~mol} \mathrm{dm}^{-3}$ was maintained to help stabilize the Ni(III) products. Stabilization of $\mathrm{Ni}$ (III) complexes in acidic media, as well as in the presence of coordinating ligands, is well-known from kinetic studies ${ }^{21,22}$. Decomposition of the tervalent species at low acidity has been attributed to intramolecular electron transfer involving $\mathrm{Ni}$ (II) ligand radical species. Ionic strength was maintained at $0.5 \mathrm{~mol} \mathrm{dm}^{-3}$ for all kinetic runs, using lithium perchlorate. Absorbance measurements were made at wavelengths chosen between 360 and $450 \mathrm{~nm}$.

\section{Results and discussion}

The ESR spectrum of the product confirms the formation of Ni(III) species (figure 1). In kinetic studies using UV-Vis spectral changes, an initial rapid decrease in the absorbance was observed followed by a slower decrease. For all the complexes under investigation, plots of $\log \left(D_{t}-D_{\infty}\right)$ versus time show two slopes corresponding to an initial fast reaction and a subsequent slow reaction. Rate constants for the second stage of the kinetics are determined from the plot of $\log \left(D_{t}-D_{\infty}\right)$ vs time. To determine the rate constants for the initial faster reaction ${ }^{26}$, the linear portions corresponding to the slower reactions are extrapolated to zero time, and subtracted point by point from $\left(D_{t}-D_{\infty}\right)$. The logarithm of this difference $\left(D_{t}-D_{c}\right)$, where $D_{c}$ is the corresponding absorbance in the extrapolated

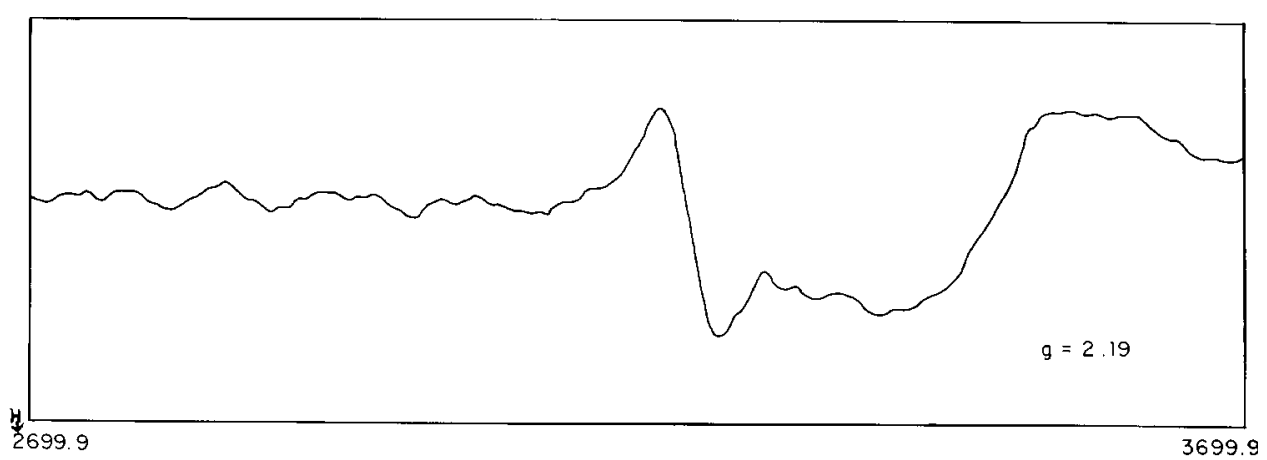

Figure 1. ESR spectrum of the reaction product of $\mathrm{NiL}^{2}-\mathrm{Na}_{2} \mathrm{~S}_{2} \mathrm{O}_{8}$ system. 
line, when plotted against time, gives a linear plot from which the rate constant for the initial stage is determined. Rates are almost independent of $p \mathrm{H}$ especially in the range $2<p \mathrm{H}<4$.

An important feature of $\mathrm{Ni}(\mathrm{II})$ macrocycles is the coexistence in solution of the high spin and low spin form, according to the interconversion equilibrium

\begin{tabular}{|c|}
\hline $\begin{array}{l}{\left[\mathrm{NiLS}_{2}\right]^{2+} \rightleftharpoons} \\
\text { octahedral } \\
\text { high spin }\end{array}$ \\
\hline
\end{tabular}

where $\mathrm{L}$ is the macrocycle and $\mathrm{S}$, any solvent molecule displaying donor properties ${ }^{23,24}$. In the solvents used, viz. water, and aqueous acetonitrile and DMF, all the reported macrocyclic complexes exist as mixtures of the two forms. This is illustrated by the presence of an absorption band centred at $450 \mathrm{~nm}$ (pertinent to the yellow, low spin chromophore) and two absorption bands centred at $330 \mathrm{~nm}$ and $530 \mathrm{~nm}$ (corresponding to the blue-violet, high spin chromophore) in the UV-Vis spectrum ${ }^{25}$ (200-800 $\mathrm{nm}$ range). A visible colour change from yellow to purple was observed initially, immediately on the addition of $\mathrm{Na}_{2} \mathrm{~S}_{2} \mathrm{O}_{8}$. Initial rapid decrease in the absorbance might be due to two simultaneous reaction, (i) the high spin form reacting with the oxidant, (ii) the high spin form is transformed into the more stable low spin form subsequent slower decrease in the absorbance possibly due to the reaction of the more stable low spin form with $\mathrm{S}_{2} \mathrm{O}_{8}{ }^{2-}$. This is illustrated from the diode-array spectra (figure 2). The overall reaction may be described as,

$$
2[\mathrm{Ni}(\mathrm{II}) \mathrm{L}]^{2+}+\mathrm{S}_{2} \mathrm{O}_{8}{ }^{2-} \rightarrow 2\left[\mathrm{Ni}(\mathrm{III}) \mathrm{L}\left(\mathrm{SO}_{4}\right)\right]^{+} .
$$

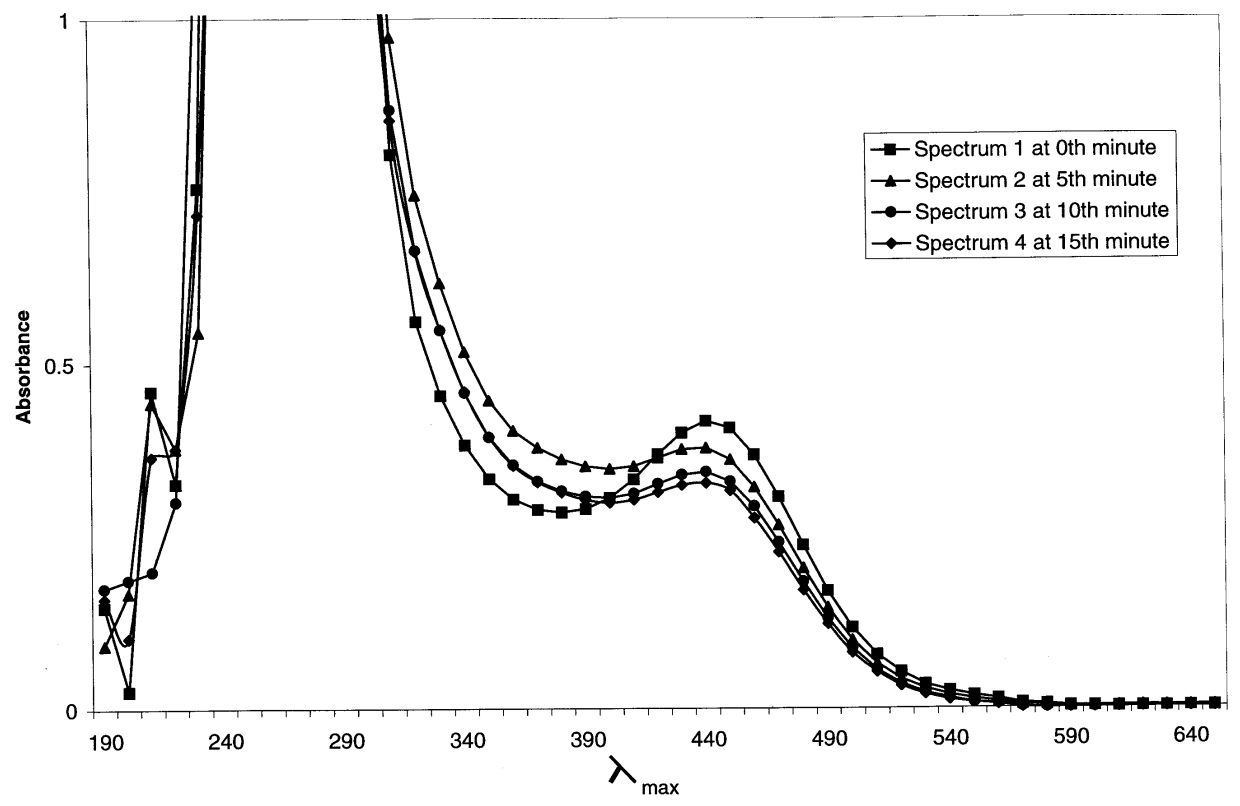

Figure 2. Diode-array spectra of $\mathrm{NiL}^{2}-\mathrm{Na}_{2} \mathrm{~S}_{2} \mathrm{O}_{8}$ system at $p \mathrm{H}=2\left(\mathrm{HClO}_{4}\right)$. 
First-order kinetics is observed for the appearance of $\mathrm{Ni}(\mathrm{III})$ products, in all the solvents studied. If $\mathrm{SO}_{4}{ }^{-}$radicals were involved in the rate-determining step during the reaction, deviation from first-order behaviour in oxidation of peroxydisulphate would have occurred ${ }^{27}$.

Thus the rate law,

$$
\text { rate }=+\frac{1}{2} \mathrm{~d}[\mathrm{Ni}(\mathrm{III}) \mathrm{L}] / \mathrm{d} t=k_{\mathrm{obs}}[\mathrm{Ni}(\mathrm{II}) \mathrm{L}]
$$

is obeyed.

Table 1 lists the observed first-order rate constants for the oxidation of all the four $\mathrm{Ni}(\mathrm{II})$ complexes, studied in aqueous medium, as a function of $\mathrm{S}_{2} \mathrm{O}_{8}{ }^{2-}$ concentration. Rates are almost independent of acid between $p \mathrm{H} 4$ and 2 (table 2), indicating the absence of protonation of the oxidant in this range. This observation is consistent with the reported lack of $\mathrm{H}$-ion dependence ${ }^{28}$ in the oxidation of iron(II) by $\mathrm{S}_{2} \mathrm{O}_{8}{ }^{2-}$ up to an acid concentration of $0.01 \mathrm{~mol} \mathrm{dm}{ }^{-3}$. The addition of a radical scavenger, allyl acetate ${ }^{29}$, caused no change in rates, within experimental error. This suggests that the ratedetermining step does not involve the $\mathrm{SO}_{4}^{-}$species.

A common mechanism (ignoring, for the moment, interchange between possible inner sphere solvent at the $\mathrm{Ni}(\mathrm{II})$ complex and peroxy disulphate) may be described schematically as ${ }^{30}$,

$$
\begin{aligned}
& {[\mathrm{Ni}(\mathrm{II}) \mathrm{L}]^{2+}+\mathrm{S}_{2} \mathrm{O}_{8}{ }^{2-} \stackrel{K_{\text {ip }}}{\leftrightharpoons}\left\{\mathrm{Ni}(\mathrm{II}) \mathrm{L}^{2+} \mathrm{S}_{2} \mathrm{O}_{8}^{2-}\right\},} \\
& \text { ion pair } \\
& \left\{\mathrm{Ni}(\mathrm{II}) \mathrm{L}^{2+} \mathrm{S}_{2} \mathrm{O}_{8}{ }^{2-}\right\} \stackrel{k_{4}}{\longrightarrow}\left[\mathrm{Ni}(\mathrm{III}) \mathrm{L}\left(\mathrm{SO}_{4}\right)\right]^{+}+\mathrm{SO}_{4}^{-}, \\
& {[\mathrm{Ni}(\mathrm{II}) \mathrm{L}]^{2+}+\mathrm{SO}_{4}^{-} \stackrel{\text { fast }}{\longrightarrow}\left[\mathrm{Ni}(\mathrm{III}) \mathrm{L}\left(\mathrm{SO}_{4}\right)\right]^{+} \text {. }}
\end{aligned}
$$

The rate law derived from this scheme is

$$
\text { Rate }=2 k_{4} K_{\text {ip }}\left[\mathrm{S}_{2} \mathrm{O}_{8}{ }^{2-}\right][\mathrm{Ni}(\mathrm{II}) \mathrm{L}]_{\mathrm{tot}} /\left(1+K_{\mathrm{ip}}\left[\mathrm{S}_{2} \mathrm{O}_{8}{ }^{2-}\right]\right) .
$$

Such a rate law is expected to show curvature in the plot of dependence of the observed first order rate constant on $\left[\mathrm{S}_{2} \mathrm{O}_{8}{ }^{2-}\right]$, if the ion pairing constant is sufficiently large. In the present system no curvature is seen in the $k_{\text {obs }}$ vs $1 /\left[\mathrm{S}_{2} \mathrm{O}_{8}{ }^{2-}\right]$ plots. This suggests that the ion-pairing constant is small and the approximation,

$$
1+K_{\text {ip }}\left[\mathrm{S}_{2} \mathrm{O}_{8}{ }^{2-}\right]=1,
$$

is valid over the range of oxidant concentrations used. Hence the rate law is simplified to

$$
\begin{aligned}
\text { rate } & =k_{\text {obs }}\left[\mathrm{NiL}^{2+}\right] \\
& =2 k_{4} K_{\mathrm{ip}}\left[\mathrm{S}_{2} \mathrm{O}_{8}{ }^{2-}\right] .\left[\mathrm{NiL}^{2+}\right] .
\end{aligned}
$$



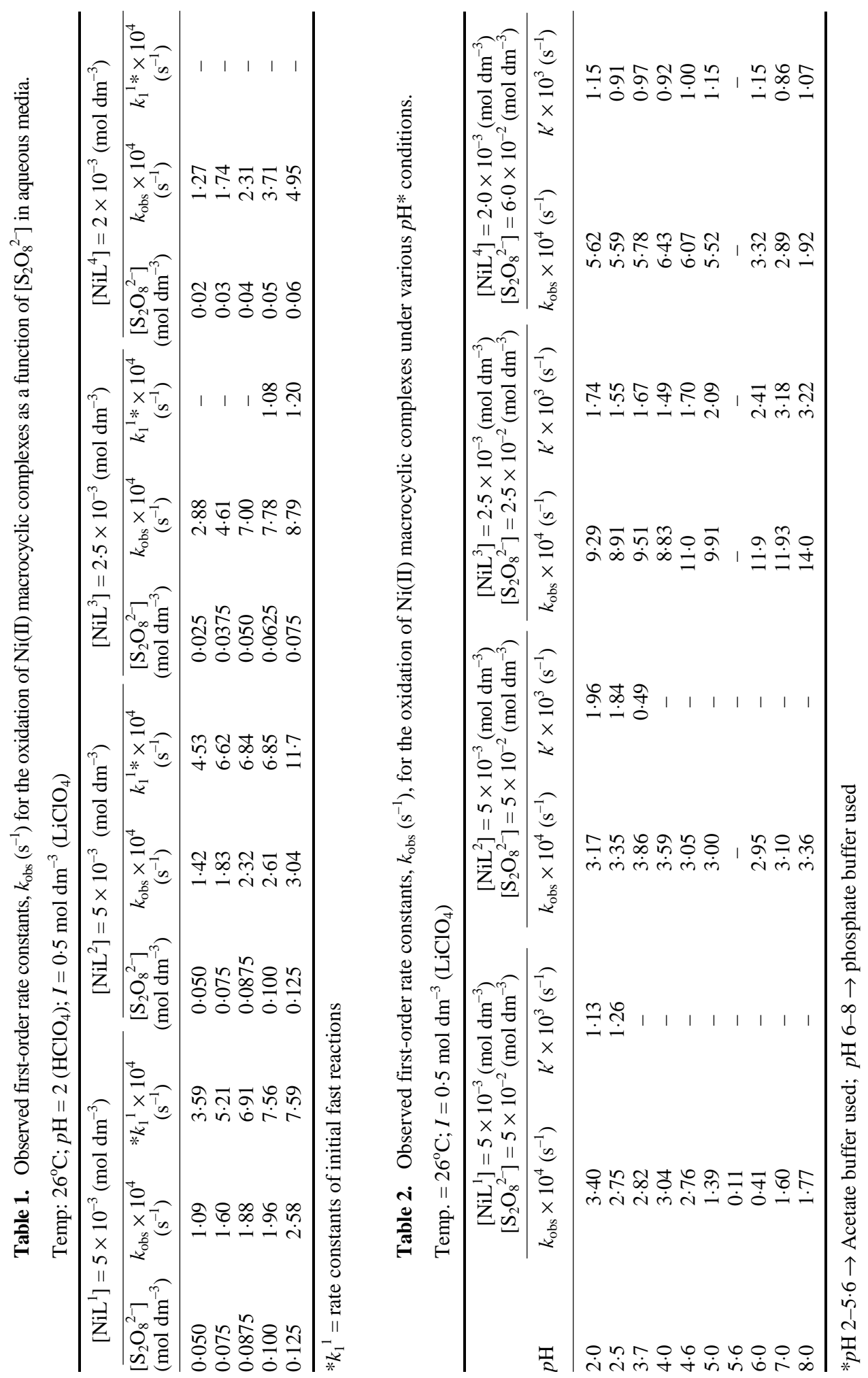


\section{1 pH effects}

The $p \mathrm{H}$ of the medium was varied from 2 to 8 using acetate buffer (up to $p \mathrm{H} \mathrm{5.6)} \mathrm{and}$

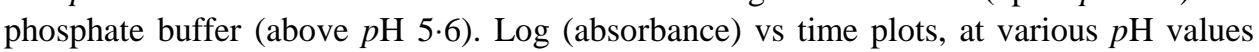
for all the four $\mathrm{Ni}(\mathrm{II})$ macrocycles studied, are linear for several half-lives at lower $p \mathrm{H}$ $(p \mathrm{H}=2)$, whereas at higher $p \mathrm{H}$ values, the linearity did not persist for longer time intervals due to the formation of $\mathrm{Ni}$ (II). The rates are almost independent of acid between $2<p \mathrm{H}<4$ (table 2).

\subsection{Stability of higher oxidation state of nickel}

An appreciable shift in the stability of oxidation state occurs when there is a change in macrocyclic ring size. An increase in ring size promotes the ease of formation of $\mathrm{Ni}(\mathrm{I})$, while rendering the oxidation to Ni(III) more difficult. The difference between the [14]ane $\mathrm{N}_{4}$ and [16]-ane $\mathrm{N}_{4}$ complexes amounts to $0 \cdot 3$ volt in terms of reduction potential ${ }^{31}$. The hole size provided by the macrocyclic ligand should probably decide the stability of the various oxidation states of the central metal ion. The greater the hole size the lesser will be the stability of $\mathrm{Ni}$ (III). The observed rate constants appear to reflect this for all the four complexes studied. This means that $k_{\text {obs }}$ values for $\mathrm{NiL}^{3}$ and $\mathrm{NiL}^{4}$ are higher compared to that of $\mathrm{NiL}^{1}$ and $\mathrm{NiL}^{2}$ because of the reduction in ring size. In general, reaction $\mathrm{Ni}(\mathrm{II}) \rightarrow \mathrm{Ni}(\mathrm{I})$ is seen to occur with greater ease than $\mathrm{Ni}(\mathrm{II}) \rightarrow \mathrm{Ni}(\mathrm{III})$. The larger $\mathrm{Ni}(\mathrm{I})$ cation can be more easily accommodated in a larger 'hole'. The 13- or 14membered ring ( $\mathrm{NiL}^{3}$ and $\mathrm{NiL}^{4}$ respectively) provides a considerably stronger ligand field for a coordinated metal ion than does the corresponding 16-membered ring $\left(\mathrm{NiL}^{1}\right.$ and $\mathrm{NiL}^{2}$ ). Also complexes of [16] $\mathrm{N}_{4}$ are much less resistant to solution decomposition than the analogous [14] $\mathrm{N}_{4}$ complexes. Further, increasing the extent of ligand unsaturation results in a stronger ligand field towards the coordinated $\mathrm{Ni}(\mathrm{II})$ ion $^{32-34}$.

\section{Acknowledgement}

One of the authors (JL) acknowledges the award of a fellowship by the University Grant Commission, New Delhi. The authors also thank Dr T Balakrishnan for encouragement. We gratefully acknowledge the spontaneous help by Prof $\mathrm{P}$ Natarajan and Prof $\mathrm{P}$ Ramamurthy of the National Centre for Ultrafast Processes, Chennai for providing the diode-array and spectral facilities.

\section{References}

1. Lindoy L F 1989 The chemistry of macrocyclic ligands complexes (Cambridge: University Press)

2. Chen X, Rokita S E and Burrows C J 1991 J. Am. Chem. Soc. 1135884

3. Kinneary J F, Albert J S and Burrows C J 1988 J. Am. Chem. Soc. 1106124

4. Fisher B and Eisenberg R $1980 \mathrm{~J}$. Am. Chem. Soc. 1027361

5. Belay M, Collin J P, Ruppert R and Sauvage J P 1984 J. Am. Soc., Chem. Commun. 1315

6. Belay M, Collin J P, Ruppert R and Sauvage J P 1986 J. Am. Chem. Soc. 1087461

7. Fujihira H, Hirata Y and Saga K 1990 J. Electroanal. Chem. 292199

8. Taniguchi I 1989 In Modern aspects of electrochemistry (eds) J O M Bockris, R E White and B E Conway (New York: Plenum) vol. 20, p. 327

9. Gosden C, Healy K P, Pletcher D and Rosas R 1978 J. Chem. Soc., Dalton Trans. 972

10. Gosden C, Kerr J B, Pletcher D and Rosas R 1981 J. Electroanal. Chem. 117101 
11. Busch D H 1978 Acc. Chem. Res. 11392

12. Haines R I and North Cott Sandra J 1992 Can. J. Chem. 702785

13. Haines R I, Park B C, Murray K and Pebbie W 1993 Can. J. Chem. 71976

14. McAuley A, Paul R, Olirbuyide N and Olesegun 1948 J. Chem. Soc., Dalton Trans. 81501

15. Haines R I and McAuley A 1981 Coord. Chem. Rev. 3977

16. Jaacobi M, Meyerstein D and Lilie J 1979 Inorg. Chem. 18429

17. Kimura M, Akazome T, Takenaka K and Kobayastu A 1980 Bull. Chem. Soc. Jpn. 531271

18. Suh M P, Kang S G, Goedker V L and Park S 1991 Inorg. Chem. 30365

19. Suh M P, Shin W, Kang S G, Lah M S and Chung T M 1989 Inorg. Chem. 281602

20. Rout A K, Patra N C and Sahoo B 1989 Indian J. Chem. A28 763

21. Haines R I and McAuley A 1981 Coord. Chem. Rev. 3977

22. Haines R I and McAulay A 1980 Inorg. Chem. 19719

23. Sabatini L and Fabbrizzi L 1979 Inorg. Chem. 18438

24. Anichini A, Fabbrizzi L, Paoletti P and Clay R M 1977 Inorg. Chim. Acta 24121

25. Abba F, De Santis G, Fabbrizzi L, Licchelli M, Lanfredi A M M, Pallvicini P, Poggi A and Ugozzoli F 1994 Inorg. Chem. 331366

26. Haim A 1964 J. Am. Chem. Soc. 862352

27. (a) Irvine D H 1959 J. Chem. Soc. 2977; (b) Benson D 1968 In Mechanisms of inorganic reactions in solution, an introduction (London: McGraw-Hill) chap 5

28. Gupta S S and Gupta Y K 1981 Inorg. Chem. 20454

29. (a) Kolthoff I M, Mechan E J and Larr E M 1953 J. Am. Chem. Soc. 75 1439; (b) Ball D L, Gutchfield M M and Edward J O 1960 J. Org. Chem. 25

30. (a) Diebler H and Eigen M 1959 Z. Phys. Chem. (Frankfurt am Main) 20 229; (b) Eigen B M and Bunsen G 1963 Phys. Chem. 67753

31. Lovecchio F V, Gove E S and Busch D H 1974 J. Am. Chem. Soc. 9610

32. (a) Sperali C R Ph D thesis, Ohio State University, Columbus, OH (b) DeHayes M L, Tait A M and Busch D H (unpublished results)

33. House D A and Curlis N F 1964 J. Am. Chem. Soc. 86223

34. Busch D H 1967 Helv. Chim. Acta (Werner Memorial Volume) 174 